\title{
Pengaruh Tes Elevasi Tungkai Secara Pasif terhadap Variasi Pletismograf untuk Penilaian Responsivitas Cairan pada Pasien yang Dilakukan Pembedahan dengan Anestesi Umum
}

\author{
Bahtiar Susanto, ${ }^{1}$ Erwin Pradian, ${ }^{2}$ Tatang Bisri ${ }^{2}$ \\ ${ }^{1}$ SMF Anestesiologi dan Terapi Intensif Rumah Sakit Umum Daerah Gunung Jati, \\ ${ }^{2}$ Departemen Anestesiologi dan Terapi Intensif \\ Fakultas Kedokteran Universitas Padjadjaran/Rumah Sakit Dr. Hasan Sadikin Bandung
}

\begin{abstract}
Abstrak
Penilaian responsivitas terhadap cairan sangat berguna untuk optimalisasi cairan perioperatif. Variasi pletismograf (respiratory variations in the pulse oximetry plethysmographic waveform amplitude; $\triangle \mathrm{POP}$ ) dan elevasi tungkai secara pasif (passive leg raising; PLR) merupakan parameter dinamis yang akurat dalam menilai responsivitas terhadap cairan. Tujuan penelitian ini adalah menilai pengaruh elevasi tungkai secara pasif terhadap variasi pletismograf untuk menilai responsivitas terhadap cairan pada pasien setelah induksi anestesi umum. Penelitian ini merupakan uji klinis pada 30 pasien yang menjalani operasi dengan anestesi umum, usia 18-60 tahun, dan status fisik American society of anesthesiologist (ASA) I atau II pada bulan Februari-Maret 2015 di Instalasi Bedah Sentral Rumah Sakit Dr. Hasan Sadikin Bandung. Penelitian ini diuji dengan uji-t berpasangan, Wilcoxon, dan uji ANOVA. Setelah dilakukan induksi anestesi umum, variasi pletismograf dicatat sebelum, saat, dan sesudah elevasi tungkai secara pasif. Hasil penelitian menunjukkan efek elevasi tungkai secara pasif akan menurunkan variasi pletismograf. Penurunan variasi pletismograf yang signifikan pada responden yang memiliki responsivitas terhadap cairan 6/30 dengan variasi pletismograf $>13 \%$ sebelum dilakukan elevasi tungkai secara pasif. Perbedaan ini bermakna secara statistik $(p<0,05)$. Elevasi tungkai secara pasif akan menurunkan variasi pletismograf yang dapat digunakan untuk menilai responsivitas terhadap cairan pada pasien yang menjalani operasi dengan anestesi umum.
\end{abstract}

Kata kunci: Anestesi umum, elevasi tungkai secara pasif, responsivitas terhadap cairan, variasi pletismograf

\section{Effect of Passive Leg Raising Test on Respiratory Variations in Pulse Oximetry Plethysmographic Waveform in Assessing Fluid Responsiveness of Surgery Patients under General Anesthesia}

\begin{abstract}
Fluid responsiveness assessments have shown to be an important matter in perioperative fluid optimization. Respiratory variations in pulse oximetry plethysmographic waveform amplitude $(\Delta \mathrm{POP})$ and passive leg raising have been shown as promising indicators due to the ability to predict fluid responsiveness. The aim of this study was to assess the effect of passive leg raising (PLR) on $\triangle \mathrm{POP}$ to predict fluid responsiveness in mechanically ventilated patients after induction of general anesthesia. This was a trialon 30 patients referred for surgery under general anesthesia, aged 18-60 years and ASA physical status I or II, during the period of February-March 2015 at the Central Surgical Installation of Dr. Hasan Sadikin General Hospital Bandung. Patients were studied immediately after the induction of general anesthesia. This trial use the paired $t$ test, Wilcoxon test, and ANOVA for statistical analysis. Vital signs and $\triangle \mathrm{POP}$ were recorded at baseline, before, and after PLR. PLR induced changes in $\triangle \mathrm{POP}$ with a $\triangle \mathrm{POP}$ greater than $13 \%$ compared to the initial PLR allowed discrimination between responders and nonresponders to $6 / 30$. There was a significant decrease in $\triangle \mathrm{POP}$ in responders when compared to the nonresponders $(\mathrm{p}<0.05) . \Delta \mathrm{POP}$ can be reduced by PLR and fluid responsiveness can be predicted noninvasively in mechanically ventilated patients during general anesthesia.
\end{abstract}

Key words: Fluid responsiveness, general anesthesia, passive leg raising, respiratory variations in the pulse oximetry plethysmographic waveform amplitude

Korespondensi: Bahtiar Susanto, dr., SpAn, SMF Anestesiologi dan Terapi Intensif Rumah Sakit Umum Daerah Gunung Jati, Jl. Kesambi No. 56 Cirebon, Jawa Barat, Mobile 081321206015, Email bahtiarsusanto@gmail.com 


\section{Pendahuluan}

Penilaian responsivitas terhadap cairan (fluid responsiveness) dilakukan untuk mengetahui status hemodinamik pasien selama dilakukan tindakan resusitasi. Responsivitas terhadap terapi cairan merupakan kemampuan jantung untuk meningkatkan volume sekuncup (stroke volume/SV) dan juga curah jantung (cardiac output/CO) sebesar $\geq 10-15 \%$ sebagai respons terhadap peningkatan beban awal jantung (preload). Penilaian responsivitas jantung terhadap pemberian cairan dapat dilakukan menggunakan parameter hemodinamik yang bersifat statis maupun dinamis ${ }^{\mathbf{1 , 2}}$

Perubahan hemodinamik sering dialami oleh pasien yang menjalani anestesi umum. Keadaan hipovolemia antara lain disebabkan oleh vasodilatasi yang merupakan efek obat anestesi, asupan cairan yang kurang, puasa preoperatif, serta kondisi yang berhubungan denganpenyakityangdiderita. Resusitasicairan sering kali dilakukan untuk mempertahankan perfusi organ pada pasien yang mengalami hipovolemia. Pada hipovolemia relatif yang disebabkan oleh vasodilatasi maka pemberian vasokonstriktor merupakan penatalaksanaan yang lebih tepat. Pemberian cairan berlebihan akan meningkatkan morbiditas dan mortalitas karena dapat terjadi komplikasi edema paru, overload cairan, hingga hipoksia jaringan. Oleh karena itu, penilaian responsivitas terhadap cairan akan menentukan penatalaksaan yang tepat pada keadaan hipovolemia, dalam hal ini pasien yang dilakukan pembedahan dengan anestesi umum. ${ }^{1,2}$

Pasien yang mengalami hipovolemia dapat dinilai secara klinis dengan tanda-tanda vital seperti tekanan darah, laju jantung (heart rate/HR), kesadaran, turgor kulit, capillary refill, tekanan arteri rata-rata (mean aterial pressure/MAP), maupun diuresis. Penilaian tersebut merupakan prediktor yang tidak dapat menggambarkan keadaan hemodinamik secara keseluruhan. ${ }^{1-3}$

Penilaian beban awal jantung atau preload tidak dapat menilai secara akurat responsivitas terhadap cairan. Parameter tersebutantaralain tekanan vena sentral (central venous pressure)
CVP), pulmonary capillary wedge pressure (PCWP), right ventricular end-diastolic volume index (RVEDVI), left ventricular end-diastolic area index (LVEDVAI), dan global end-diastolic volume (GEDV). Pada metode statis tersebut penilaian beban awal jantung berdasar atas pengukuran tekanan dan volume yang dapat dipengaruhi oleh beberapa faktor seperti tonus pembuluh darah, tekanan intratorakal, dan compliance ventrikel. ${ }^{1-4}$

Selama dua dekade terakhir telah terjadi pergeseran paradigma dalam teknik menilai hipovolemia dari pengukuran terhadap beban awal jantung kepada pengukuran responsivitas beban awal jantung secara aktual. Teknik uji beban cairan sudah menjadi standar emas untuk menilai responsivitas terhadap cairan. Teknik uji tersebut dapat dilakukan dengan cara pemberian cairan secara eksogen dari golongan kristaloid maupun secara endogen dan reversible dengan teknik elevasi tungkai secara pasif (passive leg raising/PLR). Saat dilakukan PLR akan terjadi pengisian volume darah sebanyak $\pm 450 \mathrm{~mL}$ yang berasal dari sirkulasi daerah tungkai dan splanchnic ke sirkulasi sentral. ${ }^{2,5,6}$

Parameter dinamis berdasar atas interaksi antara jantung dan paru pada pasien yang bernapas spontan maupun dengan ventilasi mekanik secara fisiologis akan menghasilkan variasi isi sekuncup. Beberapa metode yang dipakai antara lain variasi tekanan nadi (pulse pressure variation/PPV), variasi tekanan darah sistol (systolic pressure variation/SPV), variasi isi sekuncup (stroke volume variation/SVV), variasi gelombang pletismograf (respiratory variation of pulse oxymeter plethysmographic waveform/ $\mathrm{POP}$ ), arterial blood flow velocity, serta variasi respirasi dari diameter vena kava inferior dan vena kava superior. ${ }^{2-4}$

Metode alternatif yang dapat dipergunakan mengukur responsivitas terhadap pemberian cairan adalah variasi gelombang pletismograf. Beberapa hasil penelitian menjelaskan bahwa pengukuran $\triangle \mathrm{POP} \geq 13 \%$ sebelum dilakukan uji beban cairan menunjukkan responsivitas terhadap cairan yang tinggi dengan sensitivitas $84 \%$ dan spesifisitas $90 \%$ pada pasien dengan 
ventilasi mekanik. Pengukuran menggunakan teknik ini dinilai cukup efektif, akurat, serta mudah dilakukan., ${ }^{2,7,8}$ Variasi pada gelombang pletismograf dapat dihitung memakai rumus $\Delta \mathrm{POP}(\%)=(\mathrm{POP}$ maks. $-\mathrm{POP} \mathrm{min}) /.\{(\mathrm{POP}$ maks.+POP min.)/2\}. ${ }^{2,7,8}$

Tujuan penelitian ini adalah mengetahui pengaruh tes elevasi tungkai yang dilakukan secara pasif pada variasi pletismograf dalam penilaian responsivitas terhadap cairan pada pasien yang menjalani pembedahan dengan anestesi umum.

\section{Subjek dan Metode}

Penelitian ini merupakan uji eksperimental kuantitatif yang dilakukan setelah mendapat persetujuan Komite Etik Penelitian Kesehatan Fakultas Kedokteran Universitas Padjadjaran/ Rumah Sakit Dr. Hasan Sadikin Bandung. Penelitian dilakukan pada bulan FebruariMaret 2015 dengan kriteria inklusi adalah pasien berusia 18 sampai 60 tahun yang akan menjalani operasi elektif dengan anestesi umum di Instalasi Bedah Sentral Rumah Sakit Dr. Hasan Sadikin Bandung dengan status fisik menurut American Society of Anesthesiologist (ASA) kelas 1 dan 2. Kriteria eksklusi subjek penelitian adalah pasien dengan peningkatan tekanan intraabdominal dan atau intratorakal, serta prosedur amputasi tungkai. Penentuan besar sampel memakai rumus untuk penelitian kuantitatif eksperimental, diperoleh jumlah sampel 30 orang.

Penelitian dilakukan dengan mengelevasi tungkai responden secara pasif setinggi $45^{\circ}$ dalam waktu 1 menit setelah induksi anestesi dengan mempergunakan propofol $2 \mathrm{mg} / \mathrm{kgBB}$, fentanil $2 \mathrm{mcg} / \mathrm{kgBB}$, fasilitasi intubasi dengan atrakurium 0,5 mg/kgBB, kemudian pipa endotrakeal disambungkan dengan ventilator dengan memberikan volume tidal $8 \mathrm{~mL} / \mathrm{kgBB}$, frekuensi napas $12 \mathrm{x} /$ menit. Pemeliharaan anestesi dengan isofluran 2 vol\%, oksigen dan $\mathrm{N}_{2} \mathrm{O}$ dengan perbandingan $50 \%: 50 \%$. Tanda vital dan $\triangle$ POP dinilai dan dicatat sebelum,

Tabel 1 Karakteristik Umum Subjek Penelitian

\begin{tabular}{lcc}
\hline Karakteristik & Rata-rata & SD \\
\hline Usia (tahun) & 40,60 & 10,14 \\
BB $(\mathrm{kg})$ & 55,17 & 6,31 \\
TB $(\mathrm{cm})$ & 161,03 & 7,10 \\
BMI $\left(\mathrm{kg} / \mathrm{m}^{2}\right)$ & 21,27 & 1,97 \\
Pria & 14 & \\
Wanita & 16 & \\
ASA I/II & $9 / 21$ & \\
\hline
\end{tabular}

Tabel 2 Perubahan Variasi Pletismograf dan Hemodinamik Responden

\begin{tabular}{|c|c|c|c|c|c|c|c|c|c|}
\hline \multirow{2}{*}{ Kelompok } & \multicolumn{2}{|c|}{ Preinduksi } & \multicolumn{2}{|c|}{ Sebelum PLR } & \multicolumn{2}{|c|}{ Saat PLR } & \multicolumn{2}{|c|}{ Setelah PLR } & \multirow{2}{*}{$\begin{array}{c}\text { Nila } \\
\mathbf{p}\end{array}$} \\
\hline & Rata-rata & SD & Rata-rata & SD & Rata-rata & SD & Rata-rata & SD & \\
\hline$\triangle \mathrm{POP}(\%)$ & - & - & 9,27 & 3,41 & 5,63 & 2,01 & 7,20 & 2,51 & 0,01 \\
\hline POP maks. (mm) & - & - & 41,13 & 16,76 & 41,33 & 16,70 & 40,33 & 16,01 & 0,97 \\
\hline POP min. (mm) & & & 36,57 & 15,83 & 39,03 & 15,93 & 37,50 & 15,16 & 0,91 \\
\hline Sistol* & 128,20 & 9,69 & 102,43 & 7,87 & 109,63 & 6,48 & 101,07 & 7,84 & 0,01 \\
\hline Diastol* & 75,67 & 10,43 & 60,83 & 10,76 & 62,47 & 14,98 & 59,50 & 11,57 & 0,01 \\
\hline Tekanan nadi* & 53,33 & 10,81 & 41,53 & 7,60 & 45,83 & 7,80 & 41,23 & 11,18 & 0,01 \\
\hline MAP* & 93,37 & 8,77 & 74,63 & 9,14 & 78,80 & 9,46 & 73,03 & 8,96 & 0,01 \\
\hline Laju nadi** & 82,10 & 10,95 & 72,97 & 10,93 & 73,20 & 11,74 & 72,63 & 9,64 & 0,02 \\
\hline Laju napas** & 18,90 & 2,29 & 12,00 & 0,00 & 12,00 & 0,00 & 12,00 & 0,00 & 0,08 \\
\hline Saturasi (\%) & 99,10 & 0,76 & 99,63 & 0,56 & 99,60 & 0,56 & 99,57 & 0,63 & 0,98 \\
\hline
\end{tabular}

Keterangan: nilai p dihitung berdasarkan ANOVA, $\mathrm{p}<0,05=$ bermakna, ${ }^{*}(\mathrm{mmHg}),{ }^{* *}(\mathrm{x} / \mathrm{menit})$ 
Tabel 3 Responsivitas terhadap PLR

\begin{tabular}{lcc}
\hline & Responsif & Nonresponsif \\
\hline $\begin{array}{l}\text { Jumlah } \\
\text { Responden }\end{array}$ & 6 & 24 \\
$\begin{array}{l}\text { Rata-rata } \\
\Delta \text { POP (\%)* }\end{array}$ & $14,67 \pm 1,63$ & $7,92 \pm 2,15$ \\
\hline Keterangan: * sebelum PLR/sesudah induksi
\end{tabular}

saat PLR mencapai 1 menit, dan setelah PLR.

Analisis data dilakukan dengan uji analysis of variance (ANOVA) untuk melihat perubahan parameter hemodinamik dan nilai $\triangle \mathrm{POP}$, serta perubahan hemodinamik responden yang responsif dan nonresponsif menggunakan uji-t berpasangan dan Uji Wilcoxon. Semua data disajikan dalam bentuk simpangan deviasi. Kriteria kemaknaan yang digunakan adalah nilai $\mathrm{p}$, apabila $\mathrm{p}<0,05$ artinya signifikan atau bermakna secara statistika dan $\mathrm{p}>0,05$ tidak signifikan atau tidak bermakna secara statistik. Data yang diperoleh dicatat dalam formulir khusus, kemudian diolah melalui program statistical product and service solution (SPSS) versi 21.0 for windows.

\section{Hasil}

Karakteristik umum subjek penelitian dapat dilihat pada Tabel 1. Variasi pada gelombang pletismograf menurun saat PLR dilakukan dibanding dengan sebelum PLR, penurunan tersebut berdasarkan uji ANOVA bermakna secara statistika ( $\mathrm{p}<0,05$; Tabel 2$)$.

Pada penelitian ini ternyata sebagian besar responden nonresponsif terhadap pemberian cairan (Tabel 3).

Penurunan nilai $\triangle \mathrm{POP}$ diikuti peningkatan pada parameter hemodinamik yang signifikan $(>10 \%)$ antara sebelum serta saat PLR pada pasien yang responsif dengan perubahan signifikan $(\mathrm{p}<0,05$; Tabel 4). Pada pasien yang nonresponsif, penurunan nilai $\triangle \mathrm{POP}$ dan peningkatan parameter hemodinamik tidak signifikan antara sebelum dan saat PLR ( $p>0,05$; Tabel 5).

\section{Pembahasan}

Penelitian dilakukan pada 30 pasien berusia 18 sampai 60 tahun yang menjalani operasi elektif dengan anestesi umum di Instalasi Bedah Sentral Rumah Sakit Dr. Hasan Sadikin Bandung selama bulan Februari-Maret 2015. Terdapat 5 responden kategori ASA II dengan hipertensi terkontrol. Responden dengan pembedahan ginekologi mempunyai ukuran massa yang kecil sehingga tidak menambah

Tabel 4 Perubahan Variasi Pletismograf dan Hemodinamik Responden yang Responsif

\begin{tabular}{lccccccc}
\hline \multirow{2}{*}{ Parameter } & \multicolumn{9}{c}{ Responsif } & \multirow{2}{*}{ Nilai p } & \multirow{2}{*}{ Perubahan } \\
\cline { 2 - 5 } & \multicolumn{2}{c}{ Sebelum PLR } & Saat PLR & & \\
\cline { 2 - 5 } & Rata-rata & SD & Rata-rata & SD & & \\
\hline$\Delta$ POP (\%) & 14,67 & 1,63 & 7,83 & 0,98 & 0,03 & $47 \%^{* *}$ \\
POP maks. (mm) & 35,67 & 12,19 & 35,00 & 16,37 & 0,79 & \\
POP min. (mm) & 30,83 & 10,76 & 32,17 & 14,96 & 0,59 & \\
Sistol (mmHg) & 93,67 & 3,50 & 106,83 & 4,96 & 0,01 & $14 \% *$ \\
Diastol (mmHg) & 58,83 & 9,26 & 62,83 & 9,75 & 0,03 & $10,37 \%^{*}$ \\
Tekanan nadi (mmHg) & 70,00 & 7,16 & 77,33 & 7,26 & 0,01 & $10,4 \%^{*}$ \\
MAP (mmHg) & 34,83 & 7,05 & 44,00 & 8,72 & 0,01 & $26 \% *$ \\
Laju jantung (x/menit) & 75,83 & 15,41 & 77,17 & 14,37 & 0,30 & \\
Laju napas (x/menit) & 12,00 & 0,00 & 12,00 & 0,00 & 1,00 & \\
Saturasi (\%) & 99,67 & 0,52 & 99,33 & 0,52 & 0,16 & \\
\hline
\end{tabular}

Keterangan: nilai p dihitung berdasarkan uji-t berpasangan dan Uji Wilcoxon, p<0,05= bermakna, * peningkatan, ** penurunan 
Tabel 5 Perubahan Variasi Pletismograf dan Hemodinamik Responden yang Nonresponsif

\begin{tabular}{|c|c|c|c|c|c|c|}
\hline \multirow{3}{*}{ Parameter } & \multicolumn{4}{|c|}{ Nonresponsif } & \multirow{3}{*}{ Nilai p } & \multirow{3}{*}{ Perubahan } \\
\hline & \multicolumn{2}{|c|}{ Sebelum PLR } & \multicolumn{2}{|c|}{ Saat PLR } & & \\
\hline & Rata-rata & SD & Rata-rata & SD & & \\
\hline$\triangle \mathrm{POP}(\%)$ & 7,92 & 2,15 & 5,08 & 1,82 & 0,04 & $36 \% * *$ \\
\hline POP maks. (mm) & 42,50 & 17,66 & 42,92 & 16,74 & 0,12 & \\
\hline POP min. (mm) & 39,25 & 16,61 & 40,75 & 16,00 & 0,01 & \\
\hline Sistol (mmHg) & 104,63 & 7,09 & 110,33 & 6,71 & 0,07 & $5,44 \% *$ \\
\hline Diastol (mmHg) & 61,33 & 11,23 & 62,38 & 16,19 & 0,13 & $1,71 \% *$ \\
\hline Tekanan nadi (mmHg) & 75,79 & 9,34 & 79,17 & 10,03 & 0,06 & $7,13 \% *$ \\
\hline MAP (mmHg) & 43,21 & 6,88 & 46,29 & 7,69 & 0,08 & $4,46 \% *$ \\
\hline Laju jantung (x/menit) & 72,25 & 9,81 & 72,21 & 11,13 & 0,97 & \\
\hline Saturasi (\%) & 99,63 & 0,58 & 99,67 & 0,56 & 0,31 & \\
\hline
\end{tabular}

Keterangan: nilai p dihitung berdasarkan uji t berpasangan dan Uji Wilcoxon, p<0,05 = bermakna, * peningkatan, ** penurunan

tekanan intra-abdominal. Responden dengan pembedahan ortopedi ekstremitas atas.

Penurunan hemodinamik rata-rata yang signifikan terjadi setelah dilakukan induksi anestesi dibanding dengan sebelum induksi, yaitu tekanan darah sistol (20\%), diastol (20\%), MAP (20\%), tekanan nadi (22\%), dan laju jantung $(11 \%)$. Parameter hemodinamik kemudian mengalami peningkatan saat PLR. Pada penelitian ini terdapat perbedaan bermakna secara statistika pada perubahan variasi pletismograf antara sebelum dilakukan PLR dan saat dilakukan PLR $(\mathrm{p}<0,05)$. Sesuai dengan literatur dan hasil penelitianpenelitian sebelumnya, pada penelitian ini didapatkan bahwa secara fisiologis terjadi variasi dari isi sekuncup yang disebabkan oleh hubungan jantung dan paru oleh ventilasi mekanik. Variasi isi sekuncup bertambah pada saat inspirasi dan amplitudo pletismograf mencapai maksimal, sebaliknya amplitudo pletismograf menjadi minimal saat ekspirasi dan terjadi penurunan isi sekuncup. Untuk meningkatkan beban jantung awal dapat dilakukan dengan teknik PLR yang akan meningkatkan isi sekuncup, hal ini dapat dilihat dari perubahan variasi pletismograf serta parameter hemodinamik seperti tekanan arteri, tekanan nadi, maupun tekanan sistol rata-rata.

Dari penelitian didapatkan bahwa 6 responden responsif terhadap PLR, sedangkan pada kelompok nonresponsif sebanyak 24 responden yang menunjukkan lebih banyak pasien yang tidak responsif terhadap PLR. Responden yang responsif memiliki variasi pletismograf $>13 \%$ sebelum dilakukan PLR dengan penurunan variasi pletismograf yang signifikan saat PLR yang bermakna secara statistik $(p<0,05)$.

Puasa preoperatif dapat menyebabkan dehidrasi dan hipovolemia pada pasien yang akan dilakukan anestesi umum. Pasien dengan dehidrasi ringan maupun hipovolemia sering tidak terlihat jelas berdasarkan klinis maupun hemodinamik pada saat preoperatif. Anestesi umum dapat menurunkan isi sekuncup disebabkan oleh efek vasodilatasi dari agen anestesi dan blokade saraf autonom. Pada praktik sehari-hari sering dipakai metode uji beban cairan dan pengukuran CVP. Metode uji beban cairan bersifat irreversible sehingga memiliki risiko meningkatkan morbiditas dan juga mortalitas pada pasien kritis, pasien dengan edema paru, gagal jantung, dan tidak bermanfaat pada keadaan responsivitas cairan yang rendah. Tekanan vena sentral dapat dipengaruhi oleh tonus pembuluh darah, 
tekanan intratorakal, dan compliance ventrikel. Selain itu, pemasangan kateter vena sentral bukan merupakan hal yang rutin dilakukan, memerlukan keahlian khusus, komplikasi yang serius seperti pneumotoraks, serta biaya yang lebih mahal. ${ }^{2,3}$

Lebih dari 100 hasil penelitian yang telah dipublikasikan menyatakan bahwa tidak ada hubungan antara nilai CVP dan volume sirkulasi dan tidak dapat dipakai untuk menilai responsivitas terhadap cairan. Tekanan vena sentral yang tinggi tidak selalu menunjukkan kelebihan cairan. Teknik PLR merupakan teknik yang sederhana, dapat diperoleh nilai yang cepat, dan dapat digunakan pada pasien yang dapat bernapas spontan maupun dengan ventilasi mekanik serta pada pasien dengan irama jantung irregular. ${ }^{2,5}$ Pengukuran dengan metode SPV, SVV, PPV, dan variasi diameter vena kava merupakan teknik yang invasif, lebih sulit, komplikasi yang serius, memerlukan perangkat tambahan khusus, biaya yang lebih tinggi, serta penggunaannya terbatas pada indikasi medis tertentu sehingga tidak tersedia sebagai alat monitor baku anestesi di kamar operasi. ${ }^{2,5,6}$

Pada kelompok pasien yang responsif terhadap PLR, kondisi hipovolemia preoperatif ditambah efek vasodilatasi dari agen anestesi akan menyebabkan hipotensi yang signifikan saat induksi anestesi. Meningkatkan beban awal jantung dengan cara PLR diharapkan akan meningkatkan isi sekuncup $>10 \%$. Hal tersebut dapat terlihat pada perubahan hemodinamik, yaitu peningkatan tekanan arteri rata-rata, tekanan darah, maupun tekanan nadi. Sesuai siklus respirasi, isi sekuncup meningkat saat akhir inspirasi yang tergambar pada amplitudo pletismograf mencapai maksimum dan isi sekuncup yang lebih rendah terlihat amplitudo pletismograf minimum pada akhir ekspirasi. Tes PLR pada pasien dengan $\triangle \mathrm{POP} \geq 13 \%$ akan meningkatkan isi sekuncup, sedangkan tes PLR pada pasien dengan $\triangle \mathrm{POP} \leq 13 \%$ tidak akan meningkatkan isi sekuncup sehingga tes PLR akan memengaruhi nilai $\triangle \mathrm{POP}$. Pada kondisi tersebut jantung berada pada bagian menanjak dari kurva Frank-Starling. Pada akhirnya, pemberian cairan akan mencapai bagian mendatar dari kurva pada saat isi sekuncup dan parameter hemodinamik tidak akan mengalami peningkatan lagi. Pada kondisi tersebut pemberian vasokonstriktor tetap dipertimbangkan. Meskipun pemberian cairan pada kondisi yang responsif akan berguna memperbaiki hemodinamik, namun responsivitas terhadap cairan tidak selalu mengindikasikan kebutuhan pemberian bolus cairan. Pemberian cairan pada pasien yang masih responsif harus berdasar atas kondisi klinis dan hemodinamik pasien masingmasing. ${ }^{9}$

Pada pasien yang tidak responsif terhadap PLR dapat disebabkan oleh pasien berada pada kondisi normovolemia. Hal tersebut terlihat pada kondisi klinis dan hemodinamik sebelum dilakukan anestesi umum. Terdapat hasil penelitian yang menyatakan bahwa puasa perioperatif tidak menyebabkan hipovolemia yang signifikan dan perubahan hemodinamik pada pasien ASA I-III. Penelitian tersebut menggunakan teknik PLR dan perubahan isi sekuncup dinilai memakai ekokardiografi. ${ }^{10}$

Penelitian lain menyatakan bahwa volume darah setelah puasa preoperatif pada pasien yang sehat tetap normal. Penilaian volume darah dilakukan secara langsungmenggunakan teknik indocyanine green dilution. ${ }^{11}$ Selama puasa preoperatif tubuh dapat kehilangan cairan sebanyak 500-1.000 mL pada semua kompartemen tubuh yang tidak hanya terdapat pada kompartemen intravaskular yang berasal dari evaporasi sebanyak $0,5 \mathrm{~mL} / \mathrm{kgBB} / \mathrm{jam}$ dan saat diuresis $0,5 \mathrm{~mL} / \mathrm{kgBB} / \mathrm{jam}$. Hal ini bertentangan dengan pemikiran selama ini bahwa puasa preoperatif selalu menyebabkan dehidrasi dan hipovolemia yang signifikan.

Penelitian lain dilakukan pada pasien sehat dan tidak puasa yang diberian infus cairan koloid, pada posisi terlentang menunjukkan tidak satupun pasien mengalami peningkatan isi sekuncup $>10 \%$ yang dilihat menggunakan esophageal dopler. Pada kondisi normovolemia dengan posisi terlentang, jantung bekerja pada bagian mendatar dari kurva FrankStarling. ${ }^{11}$ Oleh karena itu, pemberian cairan preoperatif sebelum induksi anestesi menjadi tidak relevan dan hipotensi yang terjadi 
setelah induksi anestesi lebih tepat diberikan vasokonstriktor. ${ }^{11}$

\section{Simpulan}

Variasi gelombang pletismograf pada pasien yang menjalani pembedahan dengan anestesi umum dipengaruhi peningkatan isi sekuncup saat dilakukan teknik PLR. Hasil penelitian ini dapat memberikan informasi ilmiah yang bermanfaat mengenai salah satu cara untuk menilai responsivitas terhadap cairan pada pasien yang menjalani operasi dalam anestesi umum dengan penilaian variasi pletismograf.

\section{Daftar Pustaka}

1. Shujaat A, Bajwa AA. Optimization of preload in severe sepsis and septic shock. Crit Care Res Pract. 2012;1(1):1-14.

2. Marik PE, Monnet $\mathrm{X}$, Teboul JL. Hemodynamic parameters to guide fluid therapy. Ann Intensive Care. 2011;1(1): 1-9.

3. Monnet X, Teboul J. Assessment of volume responsiveness during mechanical ventilation: recent advances. Crit Care. 2013;17(2):217-25.

4. Magner S. Fluid status and fluid responsiveness. Curr Opin Crit Care. 2010; 16(4):289-96.
5. Monnet X, Teboul JL. Passive leg raising. Int Care Med. 2008;34(4):659-63.

6. Maizel J, Airapetian N, Lorne E, Tribouilloy C, Massy Z, Slama M. Diagnosis of central hypovolemia by using passive leg raising. Int Care Med. 2007;33(7):1133-8.

7. Cannesson $M$, Desebbe 0 , Hachemi $M$, Jacques D, Bastien 0, Lehot JJ. Respiratory variations in pulse oximeter waveform amplitude are influenced by venous return in mechanically ventilated patients under general anaesthesia. Eur J Anaesth. 2007;24(3):245-51.

8. Cannesson M, Attof Y, Rosamel P. Respiratory variations inpulse oximetry plethysmographic waveform amplitude to predict fluid responsiveness in the operating room. Anesthesiology. 2007; 106(6):1105-11.

9. Bungaard $M$, Jorgensen $C$, Secher N, Kehlet H. Functional intravascular volume deficit in patients before surgery. Acta Anaesthesiol Scand. 2010;54(4):464-9.

10. Jacob M, Chappell D, Conzen P, Finsterer $\mathrm{U}, \mathrm{Rehm} \mathrm{M}$. Blood volume is normal after pre-operative overnight fasting. Acta Anaesthesiol Scand. 2008;52(4):522-9.

11. Muller L, Biere M, Bastide S, Roger C, Zoric L, Seni G, dkk. Preoperative fasting does not effect haemodynamic status: a prospective, non-inferiority, echocardiography study. Br J Anaesth. 2014;5(112):835-42. 